\title{
AKTIVISME SOSIAL MELALUI PENGGUNAAN MEDIA SOSIAL: STUDI KASUS ASOSIASI IBU MENYUSUI INDONESIA (AIMI)
}

\author{
Nunik Maharani Hartoyo, Dandi Supriadi \\ Program Studi Jurnalistik, Fakultas Ilmu Komunikasi, Universitas Padjadjaran
}

\begin{abstract}
ABSTRAK
Asosiasi Ibu Menyusui Indonesia (AIMI) adalah organisasi nirlaba yang mengampanyekan pemberian ASI eksklusif dan mendukung kegiatan menyusui yang bertumpu pada pemanfaatan perkembangan TIK dan media sosial. Hal tersebut cukup unik sehingga peneliti merasa perlu untuk mempelajari lebih lanjut proses membangun dan menggerakkan aktivisme komunitas yang dilakukan AIMI melalui akun-akun media sosialnya. Tujuan penelitian ini adalah untuk mengetahui konstruksi pemaknaan pengurus AIMI tentang pemanfaatan media sosial dan menjelaskan proses pembangunan dan penggerakkan aktivisme komunitasnya. Dinamika proses ini diteliti dengan metode studi kasus dari Stake dengan menggunakan kerangka Teori Difusi Inovasi yang dikembangkan Everett M. Rogers. Hasil penelitian menunjukkan konstruksi makna pengurus AIMI tentang TIK dan media sosial ditanslasikan dalam pemanfaatan yang berhasil membesarkan AIMI. Pengurus memiliki karakteristik yang termasuk kategori early adopters. Prosesnya tergambar dalam tahapan innovation-decision process yang terdiri dari langkah mengoptimalisasi pengetahuan, persuasi, keputusan, implementasi dan konfirmasi. Semua tahapan ini berlangsung terus menerus dan timbal balik sebagai upaya merespon kebutuhan komunitas sekaligus mendorong efektivitas dan efisiensi dalam interaksi komunitas. Dari hasil tersebut, disarankan agar AIMI harus dapat terus memanfaatkan karakteristik pengurus untuk menjangkau kalangan late adopters dan laggard yang belum terjangkau oleh kampanye online dan offline. AIMI juga perlu mengoptimalisasi jejaringnya agar tujuan aktivisme sosialnya tercapai.
\end{abstract}

Kata-kata Kunci: AIMI, aktivisme sosial, difusi inovasi, kampanye kesehatan, media sosial

\section{SOCIAL ACTIVISM THROUGH THE USE OF SOCIAL MEDIA: A CASE STUDY INDONESIAN ASSOCIATION OF NURSING MOTHERS (AIMI)}

\begin{abstract}
Asosiasi Ibu Menyusui Indonesia (AIMI) is a non-profit organization which aims to promote and support breastfeeding in Indonesia. The formation and development of the organization is heavily relied on the utilization of ICT and social media. It is important to study how AIMI successfully benefited from the advancement of the technology in developing and generating its own kind of community activism. The objectives of this study are to find out the construction of meaning of the AIMI founders and board members towards the utilization of the social media and to explain the process of developing the community activism. The dynamics in such process is dicussed by using Stake's case study method in Everett M. Rogers 'Diffusion of Innovation framework. The results show that the construction of meaning was translated into a great use of communication technology which created a major development of the organization. The founders and board members demonstrate the characteristics of early adopters. The process is illustrated in the stages of innovation-decision process which include the stage of knowledge, persuasion, decision, implementation and confirmation. The reciprocal and continuous process is ingrained as an effort to respond to the needs of the community as well as to encourage the effectivity and efficiency in its community interaction. From the results, it is suggested that AIMI should take further advantage from the members' characteristics to broaden its outreach to the late adopters and laggards who have not been exposed by online and offline campaigns. AIMI should also broader its networks in order to achieve its social activism goals.
\end{abstract}

Keywords: AIMI, social activism, diffusion of innovation, health campaign, social media

Korespondensi: Nunik Maharani Hartoyo, S.Sos., M.Comn \& MediaSt (Mon). Program Studi Jurnalistik, Fakultas Ilmu Komunikasi Universitas Padjadjaran, Jalan Raya Bandung-Sumedang Km.21. Email: maharaninunik@gmail.com 


\section{PENDAHULUAN}

Asosiasi Ibu Menyusui Indonesia (AIMI) adalah asosiasi yang secara resmi dideklarasikan tanggal 21 April 2007 dan didirikan atas inisiasi sekelompok ibu yang memiliki kepedulian mengenai pentingnya menyusui dan memberikan ASI eksklusif. Awalnya, para ibu ini bergabung dalam sebuah milis bernama asiforbaby yang terbentuk sejak tahun 2006 untuk saling berbagi pengetahuan, informasi dan dukungan dalam konteks menyusui dan memberikan ASI eksklusif. Dengan semakin banyaknya anggota milis, maka dibuat pula pertemuan langsung (copy darat) yang ternyata melahirkan kesepakatan untuk mewujudkan aktivisme mereka pada khalayak yang lebih luas sehingga perlu dibuat sebuah organisasi yang akan mewadahinya.

Inisiasi ini kemudian berkembang cukup pesat, karena selain mengembangkan organisasi secara fisik dengan memiliki kantor pusat di Jakarta, AIMI juga memperluas daya jangkaunya. Selain mengoptimalisasi website resminya, AIMI juga memanfaatkan jejaring sosial seperti mailing list, Twitter, Facebook, dan juga fasilitas RSS untuk menyebarkan artikel yang berhubungan dengan kesehatan dalam kegiatan menyusui. Saat ini, jumlah pengikut(followers)di akunTwitter@aimi_asi telah mencapai lebih dari 73.000, dan anggota group Facebook yang di tahun 2012 baru berjumlah 13.000 anggota (Arisma \& Kaylaku, 2012), kini di pertengahan bulan Oktober 2014 ternyata telah mendekati angka 120.000 .

Lebihmenariklagi, ternyatakomunitas yang dikembangkan secara online oleh organisasi AIMI ini tidak hanya menarik perhatian kaum perempuan, namun juga telah berhasil menarik perhatian para suami untuk turut mendukung pemberian ASI eksklusif. Banyaknya suami yang menyatakan dukungannya terhadap pemberian ASI eksklusif yang digagas AIMI, pada gilirannya menjadi cikal bakal pendirian komunitas Ayah ASI (ayahasi.org) yang aktif mengampanyekan pentingnya kesadaran pemberian ASI eksklusif di Indonesia melalui akun Twitter@ID_AyahASI. Bahkan, komunitas ini tidak hanya turut berpartisipasi aktif dalam menyosialisasikan ASI eksklusif di akun Twitter dan berbagai kegiatan offline AIMI, buah aktivisme komunitas ini salah satunya terwujud dalam buku berjudul
Catatan \#AyahASI yang dijual bebas demi mempromosikan pentingnya menyusui dan memberikan ASI eksklusif pada khalayak yang lebih luas.

Kondisi ini menjadi menarik karena sejalan dengan waktu, kampanye pemberian ASI eksklusif yang digagas AIMI mampu menimbulkan efek yang melampaui target awal para pendiri AIMI hingga mampu bergerak lebih jauh dari hanya sekedar sosialisasi. Bahkan seperti yang dipaparkan Nugroho dan Syarief (2012), AIMI telah mengoptimalisasi media baru dan memperluas jaringannya tidak hanya untuk sesama organisasi masyarakat sipil, tetapi juga untuk membangun jejaring dan kemitraan dengan lembaga-lembaga pemerintahan (Departemen Kesra, Departemen Kesehatan, dll), badan-badan PBB (UNICEF, WHO, dll), dan LSM internasional (Helen Keller, CARE, Save the Children, dll). AIMI telah sangat sukses dalam kampanye untuk membantu membentuk kembali kebijakan Kementerian Kesehatan Indonesia dimana salah satu kesuksesannya adalah pelarangan dipampangnya iklan susu formula di rumah sakit pemerintah di Indonesia serta semakin banyaknya fasilitas ruang menyusui di berbagai tempat umum, area perkantoran dan instansiinstansi pemerintahan.

Selain itu, di kalangan pasangan muda perkotaan muncul pula kesadaran untuk mempromosikan ASI sebagai hal yang memiliki nilai tinggi di antara masyarakat. Menyusui kemudian dikampanyekan sebagai gaya hidup yang positif. Namun, dalam pengamatan Peneliti, kampanye pemberian ASI eksklusif juga memunculkan friksi antara pihak-pihak yang pro terhadap pemberian susu formula dengan para suporter ASI.

Perkembangan menarik ini tidak akan terjadi apabila AIMI tidak menggunakan jejaring sosial di internet dalam menyosialisasikan informasinya. Kemudahan yang diberikan oleh media sosial dengan teknologi komunikasi digitalnya membuat komunitas yang dibentuknya sangat mudah untuk berkembang. Setiap anggota dengan mudah dapat menyebarkan kampanyenya melalui jaringan komunikasi di media sosial masing-masing. Bahkan, lahirnya pengurus AIMI di level daerah pun ternyata diinisiasi oleh interaksi di media sosial. Karenanya, pemanfaatan media sosial dengan beragam fitur dan fasilitasnya 
telah memungkinkan masyarakat untuk mengakses informasi dengan mudah kapan saja dan di mana saja, dapat berbagai pengetahuan dan pengalaman, serta mengunduh artikel yang relevan dengan kebutuhannya.

Hal ini menunjukkan betapa pemanfaatan teknologi komunikasi pada saat ini memiliki efek yang sangat luas. Selain itu, teknologi komunikasi dalam bentuk media sosial seperti yang dibahas dalam penelitian ini memungkinkan interaksi manusia untuk terus berkembang sehingga melahirkan pola dan strategi komunikasi baru, baik itu dalam ranah komunikasi kelompok, komunikasi publik, komunikasi organisasional, ataupun kampanye aktivisme dan propaganda. Kondisi inilah yang menarik sehingga perlu ditelusuri seperti apa sebenarnya pemanfaatan media sosial yang digagas oleh para pengurus organisasi AIMI. Menarik juga untuk dipelajari, seperti apa usaha AIMI dalam membentuk komunitas peduli ASI melalui jaringan media sosial sehingga berkembang seperti sekarang ini. Kasus AIMI ini juga secara spesifik memiliki keunikan karena semua pengurus yang terlibat dalam kegiatan aktivisme sosial di bidang kesehatan ini sebagian besar tidak memiliki latar belakang ilmu kesehatan dan bekerja secara sukarela.

Aktivisme sosial yang dimaksud dalam penelitian ini adalah semua kondisi yang ada di saat sebuah aktivitas sosial berlangsung yang memungkinkan terjadinya sebuah perubahan sosial, yang dalam hal ini terjadi dalam lingkungan komunikasi via internet. Salah satu ciri khas media sosial adalah bangkitnya potensi kekuatan horizontal dalam mendesakkan perubahan. Meski demikian, Malcolm Gladwell (2010) misalnya, menggarisbawahi bahwa aktivisme di media sosial cenderung dibesar-besarkan dan tidak akan menghasilkan perubahan sosial dalam tataran praktis. Berdasarkan pemikiran Gladwell, sekelompok peneliti (Rotman, et al., 2011) mengategorikan jenis aktivisme yang dimungkinkan internet dalam dua kategori, yakni practical activism dan slacktivism. Practical activism didefinisikan sebagai,

"the use of a direct, proactive and often confrontational action towards attaining a societal change," sementara slacktivism diartikan sebagai "low-risk, low-cost activity via social media, whose purpose is to raise awareness, producechange, orgrantsatisfaction to the person engaged in the activity."

Aktivisme sosial yang dikembangkan Pengurus AIMI menjadi unik karena justru berada dalam irisan keduanya. Aktivisme Pengurus AIMI adalah aktivisme yang langsung, proaktif, namun tidak bersifat konfrontatif dalam mendesakkan perubahan sosial. Inilah yang menyebabkan fenomena ini menarik untuk ditelaah lebih jauh.

Berdasarkan pemaparan di atas, maka fokus utama penelitian ini adalah untuk menelusuri "bagaimana pengurus organisasi Asosiasi Ibu Menyusui Indonesia (AIMI) membentuk dan menggerakkan komunitas untuk mempromosikan pemberian Air Susu Ibu (ASI) eksklusif dan mendukung kegiatan menyusui melalui media sosial?"

Rumusan tersebut akan dijabarkan dalam konstruksi untuk mencapai tujuan penelitian ini, yaitu untuk mngetahui konstruksi pemaknaan pengurus organisasi AIMI tentang pemanfaatan media sosial dalam aktivisme sosial mereka dan menjelaskan proses pembangunan dan penggerakkan aktivisme sosial komunitas AIMI dari perspektif difusi-inovasi teknologi komunikasi.

\section{METODE PENELITIAN}

Untuk menjawab pertanyaan penelitian di atas, peneliti menggunakan pendekatan studi kasus Stake (2005, p. 443) mengatakan bahwa studi kasus dapat menjawab signifikansi/ manfaat sosial penelitian yang ingin dicapai, yaitu memperkaya informasi mengenai bagaimana pengurus AIMI membentuk dan menggerakkan aktivisme komunitas untuk mendukung pemberian ASI eksklusif dan menyusui melalui media sosial. Diharapkan, studi kasus dapat membantu para pembaca (hasil penelitian) dalam mengkonstruksikan pengetahuan.

Data primer diperoleh dari informan yang merupakan Pendiri dan Pengurus aktif AIMI melalui proses wawancara mendalam dan pengamatan dengan tujuan memahami perspektif informan mengenai makna media sosial bagi mereka dan bagaimana mereka memanfaatkannya untuk membentuk dan menggerakkan aktivisme komunitas melalui media sosial tersebut. Data sekunder berupa jejak publikasi digital di ruang media sosial yang digunakan oleh para pengurus AIMI 
juga diperlukan untuk memberikan kedalaman pemahaman terhadap perspektif informan tadi. Selain itu, data sekunder juga akan diperoleh melalui kuesioner yang disebarkan kepada pengguna akun-akun media sosial AIMI. Triangulasi dalam penelitian ini dilakukan dengan membandingkan data-data yang berasal dari wawancara dengan informan utama, rekam jejak publikasi dan interaksi informan utama dengan pihak-pihak lain di media sosial, serta data-data yang berasal dari wawancara dengan informan pendukung atau orang-orang yang ada di sekitar kehidupan informan utama.

\section{HASIL DAN PEMBAHASAN}

Berger dan Luckmann menyatakan bahwa realitas adalah hasil konstruksi sosial. Demikian pula dengan realitas perkembangan dan pengembangan teknologi yang juga merupakan hasil bentukan masyarakat. Ini sejalan dengan pernyataan Lievrouw dan Livistone (2006). bahwa munculnya inovasi dan teknologi merupakan bagian dari proses konstruksi sosial sehingga tidak bisa dilepaskan begitu saja dari proses-proses sosial disekitarnya. Teknologi dalam hal ini merupakan hasil hubungan timbal balik yang saling membentuk antara pengembangan teknologi dengan praktikpraktik sosial, sehingga antara teknologi dan praktik sosial sifatnya saling menentukan.

Kehadiran TIK bersama-sama dengan semakin masifnya penetrasi teknologi selular di Indonesia, menjadi momentum berharga dalam mempopulerkan media sosial di Indonesia. Platform teknologi yang dimungkinkan oleh kehadiran Internet dan media sosial menyebabkan kegiatan promosi dan edukasi menjadi lebih mudah untuk disebarluaskan. Namun demikian, terdapat fakta menarik, bahwa karakteristik khas media sosial yang memungkinkan pengguna menjadi aktor aktif dalam proses produksi dan konsumsi pesan, membuat hasil akhir dari komunikasi media sosial tidak selalu sesuai dengan tujuan awal. Itu pula yang terjadi dalam kampanye ASI eksklusif oleh AIMI melalui media sosial.

Sebelum memaparkan proses AIMI dalam membentuk dan menggerakkan aktivisme komunitas melalui media sosial, maka perlu terlebih dahulu dipaparkan karakteristik subjek penelitian yang menjadi informan, yaitu Pendiri dan Pengurus aktif AIMI. Berdasarkan karakteristik demografis dan psikografis Pengurus AIMI, sebagian besar pengurus AIMI berasal dari kalangan ekonomi atas dengan tingkat penghasilan di atas 15 juta per bulan, di atas kategori kelas menengah Indonesia menurut versi Bank Dunia tahun 2011 (Thajeb, 2013). Selain itu, karakteristik Pengurus AIMI yang berada dalam rentang usia 30-40 tahun, memiliki tingkat pendidikan minimal Strata 1 dan tergolong dalam kelas sosio ekonomi AB.

Secara psikografis, Pengurus AIMI adalah early adopters TIK yang memiliki empati tinggi, menyukai tantangan dan mampu menghadapi tekanan ketidakpastian dan berkepribadian sosial. Dalam segi gaya hidup, Pengurus AIMI memiliki karakteristik kosmopolit, memiliki jejaring personal dan professional yang luas lintas batas geografis serta senang dan aktif berorganisasi. Sementara dalam segi pola konsumsi media, Pengurus AIMI mengonsumsi beragam jenis media untuk memenuhi beragam kebutuhan informasinya, menghabiskan waktu berinternet $>2 \mathrm{jam} /$ hari serta memiliki akun personal di beberapa laman media sosial. Selain itu, Pengurus AIMI juga mengonstruksikan media sosial sebagai platform yang mampu menyediakan keunggulan dalam segi nilai ekonomis, memiliki daya jangkau yang luas serta menawarkan kemudahan koordinasi dan organisasi sehingga lebih hemat waktu. Hal ini tentu sesuai dengan karakteristik Pengurus yang memiliki latar belakang profesi beragam dan tetap ingin berkontribusi dalam mendesakkan perubahan sosial tanpa harus meninggalkan aktivitas utamanya.

Karakteristik internet yang sangat fleksibel, memungkinkan para penggunanya untuk terusmenerus menembus batas-batas teknologi demi memperoleh manfaat maksimal sebelum akhirnya dianggap aus, usang dan ditemukan teknologi baru yang lebih adaptif dalam menjawab tantangan jaman dan kebutuhan pengguna. Ini pula yang dirasakan oleh para informan. Terus menerus berproses dan belajar bersama adalah cara yang dikembangkan oleh pengurus dalam membangun dan menggerakkan komunitas AIMI. Mencermati karakteristik masing-masing media sosial, kelebihan dan kekurangannya dalam membangun interaksi dengan khalayak adalah sebuah keharusan agar AIMI dapat menjangkau sebanyak mungkin kalangan. Bila di tahun 2006 media sosial yang sedang naik daun dan efektif di kalangan kaum 


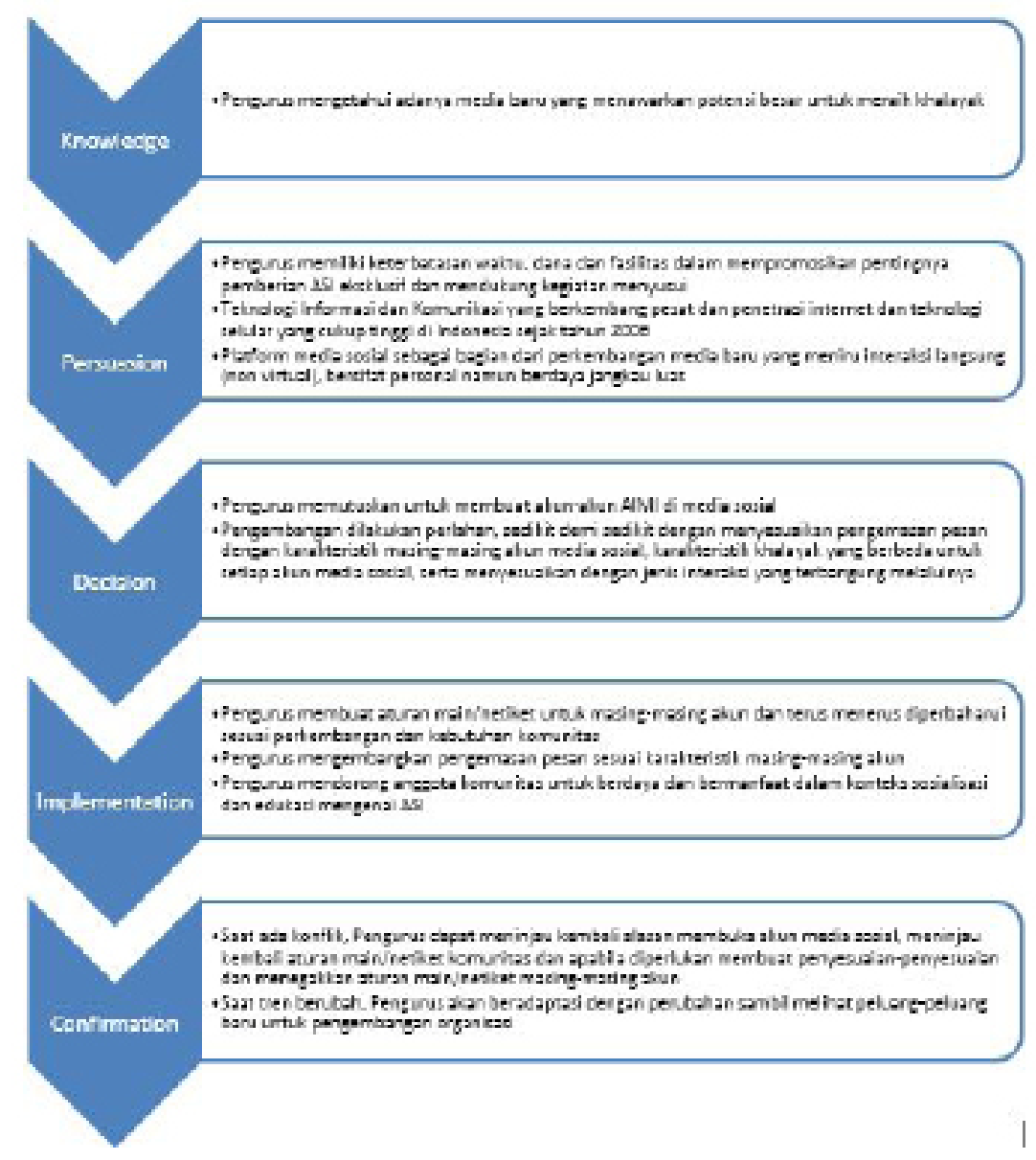

Gambar 1 Proses Tahapan Inovasi-Keputusan Pengurus AIMI dalam Membangun dan Menggerakkan Aktivisme Komunitas AIMI melalui Media Sosial

(Sumber: Hasil penelitian dengan memodifikasi model dari Rogers)

muda di kota-kota besar adalah komunikasi melalui saluran milis, maka keputusan untuk membangun komunitas peer-to-peer support melalui milis ternyata menjadi keputusan yang monumental. Melalui milis asiforbaby inilah embrio organisasi AIMI terbentuk hingga akhirnya dideklarasikan secara resmi di tahun 2007. Di tahun 2007 media sosial Facebook mulai mendapatkan momentumnya di Indonesia, AIMI pun tak ketinggalan segera membuat laman Group dengan nama Asosiasi Ibu Menyusui Indonesia (AIMI) meski tak segera dikelola dengan baik.

Di tahun 2009-2010 saat media sosial Twitter mulai meraih popularitas, AIMI pun ikut membuat akun dan ternyata melalui akun inilah AIMI mulai mendapatkan momentumnya sehingga nama AIMI mulai identik sebagai organisasi yang peduli pemberian ASI eksklusif dan serba serbi menyusui. Akun@aimi_asi pun mendapatkan banyak pengikut, mulai menjadi pembicaraan di kalangan kaum dewasa muda bahkan kampanye menyusui sebagai gaya hidup pun menjadi sangat popular saat disebarluaskan melalui akun Twitter ini.

Setelah akun@aimi_asi di Twitter menjaring banyak pengikut, pengurus pelanpelan mulai membenahi akun grup di laman Facebook mengingat potensi besar yang dimiliki oleh Facebook. Tingkat penetrasi Facebook yang tinggi di Indonesia, relatif memiliki daya jangkau yang lebih luas dibandingkan dengan Twitter, serta karakteristik khusus Facebook mampu menawarkan jenis interaksi yang berbeda dengan pengguna adalah alasanalasan yang membuat pengurus AIMI mulai berkonsentrasi membenahi akun Facebook. Kini, akun group AIMI di Facebook tidak hanya semakin berlipat ganda jumlah anggotanya, namun juga memiliki traffic interaksi yang sangat tinggi dan memiliki pola interaksi khas yang berbeda dengan akun media sosial lainnya.

Meski AIMI banyak melakukan diseminasi informasi, membangun komunitas dan 


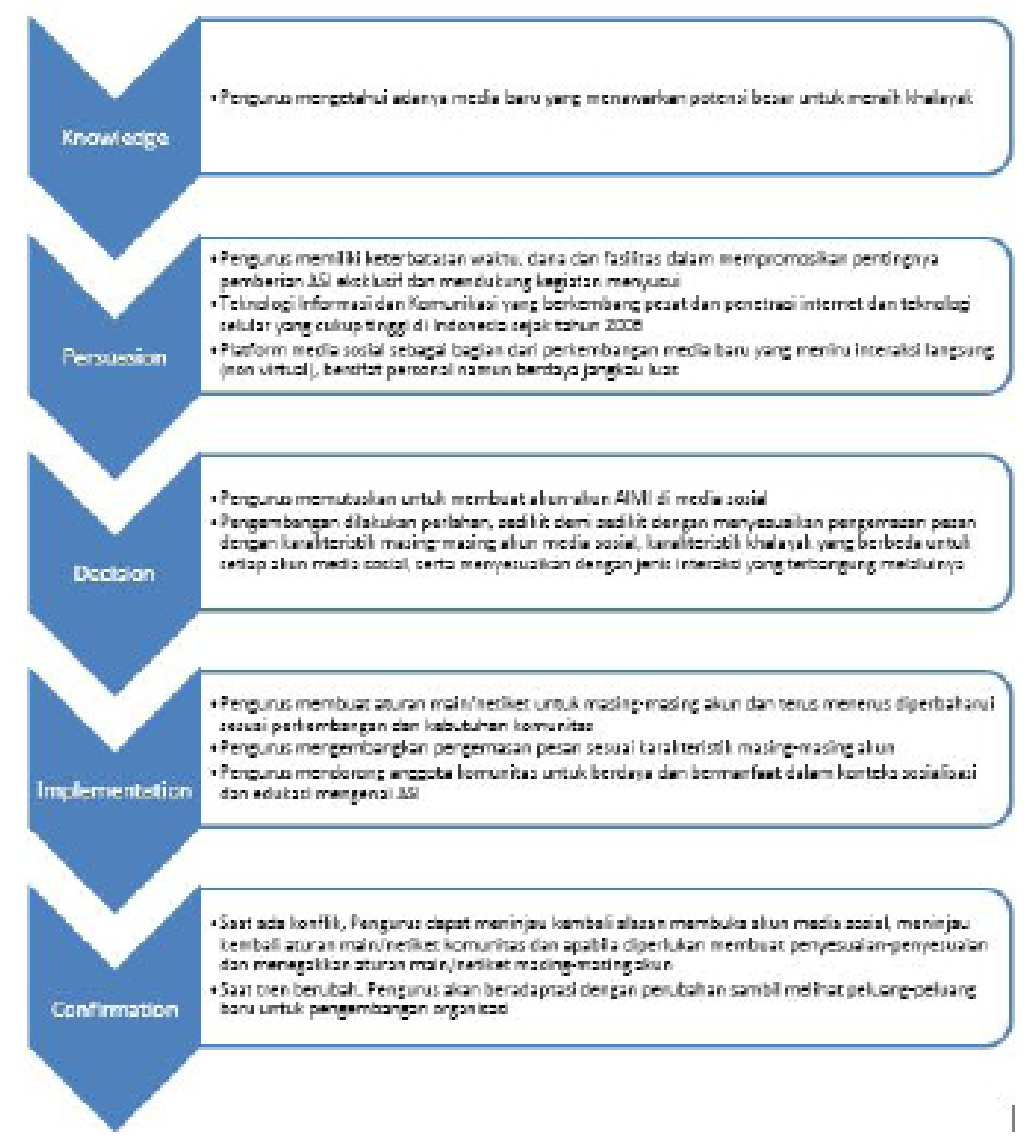

Gambar 2 Proses Tahapan Inovasi-Keputusan Anggota Komunitas AIMI untuk Terlibat Melalui Media Sosial (Sumber: Hasil penelitian dengan memodifikasi model dari Rogers)

merencanakan kegiatan melalui akun-akun media sosial, AIMI sebenarnya memusatkan seluruh informasi organisasi di website resmi organisasi: www.aimi-asi.org. Berbagai rujukan dan informasi penting berasal dan dipusatkan dalam website resmi dan kemudian diseminasikan melalui proses pengemasan yang spesifik, disesuaikan dengan karakteristik masing-masing akun media sosial. Sebagai contoh, saatkini orang mulai jenuhmenggunakan Twitter dan beralih pada akun media sosial Path, pengurus AIMI pun melihat peluang untuk memasuki media sosial ini melalui kemasankemasan pesan ilustrasi (infografis) yang singkat padat dengan dilengkapi tautan laman yang berisi informasi lengkap. Strategi ini jelas bahwa pengurus AIMI selalu memperhatikan dan mengikuti tren serta terus menerus berupaya mengantisipasi perubahan tren tersebut dengan mencoba mengenali karakteristik uniknya lalu mengemas pesan-pesan kampanyenya sesuai dengan keunikannya tersebut.

Hasilnya, AIMI berhasil membangun kesadaran pentingnya pemberian ASI eksklusif karena menitikberatkan pada proses pengemasan pesan yang terus menerus disesuaikan dengan karakteristik khalayaknya serta mengadaptasi karakteristik media sosial yang digunakannya. Lebih dari itu, AIMI juga berhasil mengembangkan pola interaksi peer-to-peer support dimana seluruh anggota/pengikut akun dapat saling membantu memberikan informasi dan dukungan yang tepat dengan intervensi minimal dari pengelola akun. Interaksi peer-topeer support yang dihasilkan oleh setiap media sosial pun ternyata berbeda satu sama lain.

Karakteristik demografis dan psikografis Informan termasuk di dalamnya gaya hidup dan pola konsumsi media apabila disandingkan dengan hasil wawancara, memiliki banyak kesamaan dengan konsep yang dikembangkan E. M. Rogers dalam Teori Difusi Inovasi. Secara ringkas, Rogers mendefinisikan difusi inovasi sebagai a particular type of communication in which the message content that is exchanged is concerned with a new idea (Rogers, 2003). Dalam teori ini, terdapat dua konsep utama yakni difusi yang bermakna proses dimana inovasi dikomunikasikan melalui saluran tertentu kepada anggota sebuah sistem sosial 


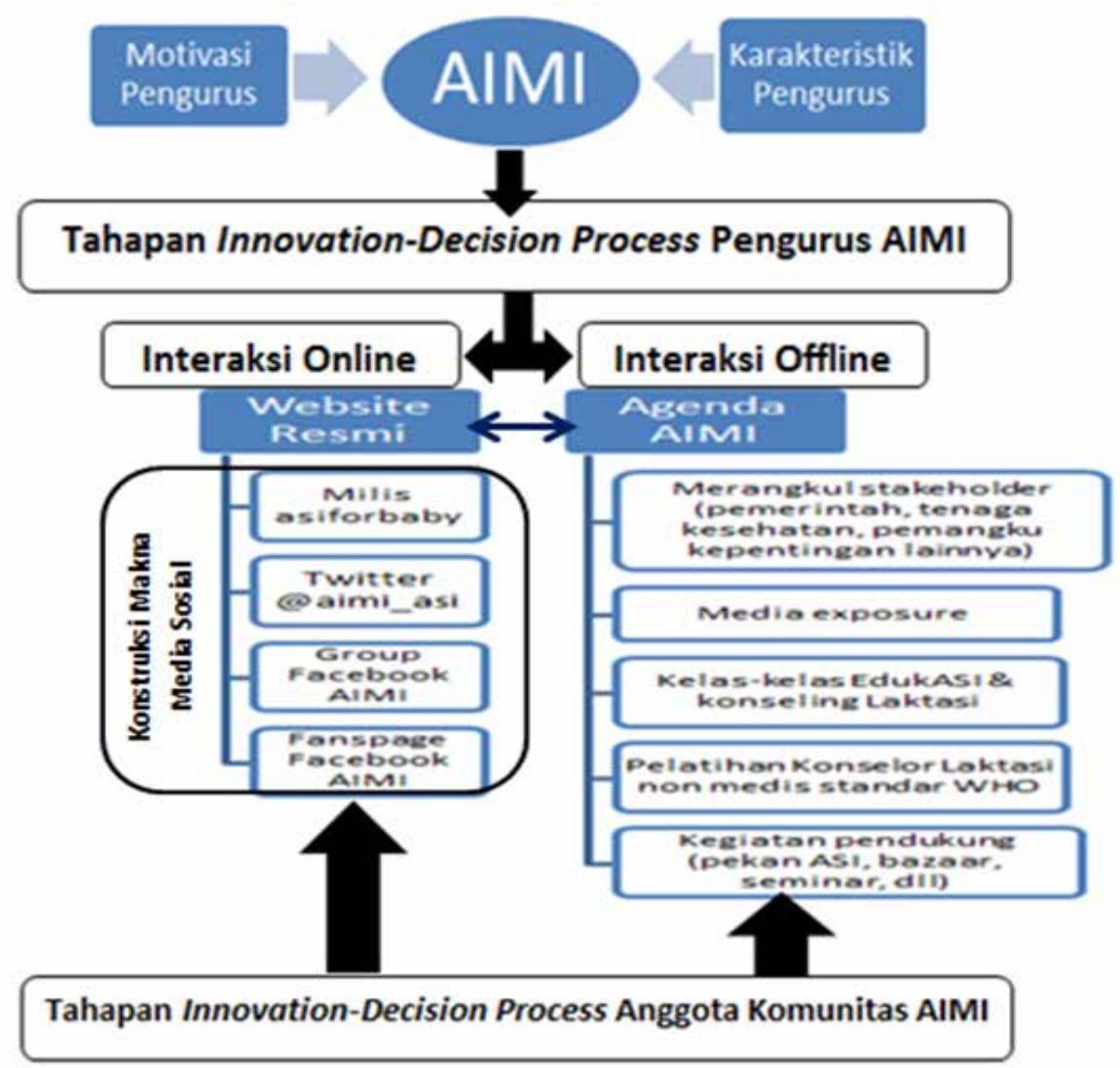

Gambar 3 Proses Pengurus AIMI Membangun \& Menggerakkan Komunitas AIMI Melalui Media Sosial (Sumber: Hasil penelitian)

dalam jangka waktu tertentu, serta inovasi yang berarti ide, praktik atau objek yang dianggap memiliki nilai kebaruan oleh individu atau kelompok adopsi tertentu (Cain \& Mittman, 2002). Berdasarkan penjelasan tersebut, proses membangun dan menggerakkan komunitas AIMI melalui media sosial dibahas dalam sepuluh konsep kunci dalam dinamika difusi inovasi yang kami sarikan dari pemaparan Rogers (2003; p. 11 - 24) sebagai berikut:

Pertama, Relative Advantage. Pemanfaatan teknologi informasi dan komunikasi termasuk di dalamnya pemanfaatan perkembangan media baru oleh Informan dianggap memiliki keunggulan relatif tinggi terutama bila dilihat dari nilai ekonomisnya. Dalam hal ini, AIMI menyadari bahwa internet dan media sosial mengedepankan kesederhanaan dalam upaya penyebaran informasi mengenai pentingnya menyusui dan pemberian ASI ekslusif serta mampu menjangkau khalayak ramai menembus batas-batas geografis (Arisma \& Kaylaku, 2012).

Kedua, Trialability. Pengadopsi memutuskan untuk mengadopsi inovasi melalui pengalaman personal terutama saat Informan mencoba menyebarluaskan agenda-agenda kampanyenya melalui beragam saluran media sosial. Karakteristik pengurus AIMI yang mengikuti aktif mengikuti perkembangan teknologi, senang mencoba hal-hal baru termasuk di antaranya mencoba platform media sosial untuk keperluan individu memberikan pertimbangan tersendiri bagi Informan untuk memutuskan kelayakan mengadopsi platform media sosial dalam pengembangan dan perluasan daya jangkau agenda organisasi AIMI.

Ketiga, Observability. Informan mengamati bagaimana kekhasan masing-masing platform media sosial dapat dimanfaatkan dengan memanfaatkan pengalaman pribadi maupun dengan mendiskusikannya dengan pihak-pihak lain atau mengamati bagaimana organisasi lain memanfaatkan media-media sosial. Melalui hasil pengamatan, Informan dapat memutuskan jenis-jenis informasi serta pengemasan pesan macam apa yang dapat dikembangkan dan diseminasikan melalui masing-masing saluran.

Keempat, Communication Channels. 
Pemahaman mengenai potensi internet dan media sosial di Indonesia menjadi dasar argumentasi AIMI dalam mempromosikan dan mendukung kegiatan menyusui melalui media sosial. Data menunjukkan bahwa di tahun 2013, tercatat 270 juta nomor selular (rerata 1.33 nomor per pelanggan) di Indonesia (Asosiasi Penyelenggara Jasa Internet Indonesia , 2012). Penetrasi telepon pintar (Smartphones) juga tercatat meningkat seiring dengan semakin populernya penggunaan netbook, tablet dan laptop. Kementrian Komunikasi dan Informasi menurut Lupiyanto (2014), mencatat bahwa pada November 2013 sebanyak 28\% penduduk Indonesia telah menggunakan Internet, dengan pengguna akun Facebook tercatat 65juta dan 19,5 juta penduduk telah memiliki akun Twitter. Penetrasi Internet dan media sosial dilaporkan terkonsentrasi di wilayah Barat Indonesia, terutama di wilayah Pulau Jawa dan $83.4 \%$ dari jumlah tersebut bermukim di perkotaan dan area urban. Lansekap digital Indonesia didominasi oleh kaum muda dimana 56\% dari total pengguna berada dalam rentang usia 16-24 tahun. Sejalan dengan semakin meningkatnya jumlah pelanggan layanan seluler disertai penetrasi telepon pintar yang tinggi di Indonesia, tercatat $87 \%$ akses ke akun-akun media sosial dilakukan melalui telepon genggam (Hartoyo \& Sirait, 2014). Karakteristik media sosial yang merupakan perpaduan antara saluran massa dan interpersonal menawarkan kekhasan yang mampu memberikan manfaat optimal dalam penyebaran agenda AIMI. Kecepatan dan efektivitas difusi pesan yang menyerupai saluran media massa dibarengi oleh kemampuan interaksi interpersonal yang efektif dalam mempersuasi individu untuk mengadopsi ide baru. Potensi-potensi yang dipaparkan Rogers (2003, p. 18) ini mengejawantah dalam saluran komunikasi yang dipilih AIMI, yakni Internet dan media sosial.

Kelima, Homophilous Group. AIMI mengedepankan kesamaan pengalaman sebagai ibu yang ingin memberikan anakanaknya hal terbaik sejak masa keemasan tumbuh kembangnya. Peer-to-peer support yang dikembangkan pada dasarnya adalah mother-to-mother support, dimana persamaan pengalaman dijadikan landasan berpijak untuk menyebarluaskan agenda AIMI, yakni mempromosikan dan mendukung pemberian ASI eksklusif kepada masyarakat Indonesia.
Hal ini terbukti efektif karena manusia lebih cenderung mudah dipersuasi saat ditempatkan sebagai individu, karena menurut Cain dan Mittman (2002, p. 16), it is valuable to speak to potential adopters from their own perspective and show that you understand their daily challenges.

Keenam, Pace of Innovation/Reinvention. Meski Facebook memiliki penetrasi yang lebih luas daripada Twitter, AIMI justru mendapatkan momentum besarnya sebagai organisasi melalui akun@aimi_asi.Namun, sejalan dengan waktu, perkembangan Twitter di Indonesia mengalami kejenuhan yang dibarengi oleh munculnya media sosial baru dengan karakteristik yang berbeda yang mulai menuai popularitas di kalangan tidak hanya early adopters, namunjuga early majority seperti Path. Saat akun Twitter mulai mengalami stagnasi, akun grup AIMI di laman Facebook justru semakin hidup dengan bergabungnya late majority dalam keanggotaan grup AIMI di Facebook. Terbukti, bila di tahun 2012 anggota grup AIMI di Facebook masih berkisar di angka 13.000 (Arisma \& Kaylaku, 2012), kini di tahun 2014, anggota grup telah mencapai 116.696 orang.

Hal ini tentu menuntut aksi nyata dari Pengurus untuk memanfaatkan momentum agar dapat memberikan hasil optimal. Beruntung, sejak tahun 2012, pengurus AIMI terus menerus melakukan perbaikan pada pola interaksi di laman Facebook sehingga anggota dan Pengurus sama-sama mendapatkan manfaat dan meminimalisir efek negatif yang muncul sebagai akibat dari interaksi anggota yang sangat beragam dan tersebar. Aturan main/netiket terus menerus diperbaharui, dokumen-dokumen penting terkait permasalahan menyusui terus dirapikan dan diperbaharui dan diunggah di laman grup agar anggota dapat mengakses informasi-informasi tersebut kapan saja dan di mana saja. Interaksi antar anggota diarahkan pada pemberdayaan anggota (saling bertukar informasi dan pengalaman) serta pemberian dukungan psikologis. Sementara itu, interaksi anggota dan Administrator grup diarahkan pada pemberian dukungan psikologis, rujukan informasi kesehatan dan konseling laktasi, menengahi apabila terdapat kesalahpahaman atau bahkan konflik di antara anggota serta penegakan peraturan grup.

Jelas, praktik-praktik reinvention ini memerlukan keterampilan dan pengetahuan 
khusus untuk menangkap pola interaksi dan umpan balik anggota di dalam masing-masing media sosial. Pengurus juga secara aktif terus menerus mengantisipasi dan melakukan langkah-langkah penyesuaian berdasarkan hasil interaksi, pengamatan dan umpan balik. Menurut Cain dan Mittman (2002, p. 19), penemuan kembali adalah indikator yang baik yang menggambarkan bahwa inovasi tersebut telah dimanfaatkan dan digunakan melampaui tujuan awalnya. Upaya-upaya perbaikan yang dilakukan Pengurus terbukti mampu memberikan kontribusi nyata dalam konteks pengembangan AIMI sebagai organisasi serta dalam konteks penyebaran agenda-agenda organisasi.

Ketujuh, Norms, Roles and Social Networks. Dalam konteks komunikasi kesehatan tradisional, norma yang berlaku adalah tenaga medis dan otoritas-otoritas kesehatan seperti Kementrian Kesehatan dan institusi penyedia jasa dan layanan kesehatan lainnya adalah para pemangku kepentingan yang memiliki otoritas penuh untuk mempromosikan dan mendukung pemberian ASI eksklusif. Kini, masyarakat telah pula memainkan peran pentingnya sebagai pemangku kepentingan dalam isu-isu kesehatan termasuk di dalamnya isu pemberian ASI eksklusif. AIMI telah mendobrak batasanbatasan itu melalui program pemberdayaan dan kampanye-kampanyenya dalam tujuh tahun terakhir.

Di awal pendirian Pengurus AIMI mengakui bahwa seringkali sulit meyakinkan pihakpihak lain bahwa AIMI dan konselor laktasi non medis juga dapat membantu memberikan kontribusi nyata serta memiliki otoritas untuk membicarakan isu ASI eksklusif dan kesehatan ibu dan anak. Resistensi tidak hanya datang dari tenaga-tenaga kesehatan yang merasa AIMI tidak memiliki otoritas baik secara akademis maupun professional untuk berkiprah di sektor kesehatan, namun juga harus menghadapi resistensi masyarakat yang belum paham mengenai Konselor Laktasi non medis yang memiliki sertifikasi khusus untuk membantu memberikan konseling hingga derajat tertentu. Karenanya, AIMI memulai sepak terjangnya dengan misi menjadikan AIMI organisasi rujukan di tingkat nasional terkait isu menyusui.

Berkat kerja keras dan strategi yang tepat seperti mengombinasikan kegiatan online dan offline, mengikuti perkembangan dan selalu berupaya beradaptasi dengan perubahan serta bekerja sama dengan para pemangku kepentingan strategis lainnya, AIMI berhasil menjalankan misi tersebut dalam waktu relatif singkat.

Kedelapan, Opinion Leader. Memiliki akses akan ide-ide baru melalui akses media yang dimilikinya, relatif lebih kosmopolit, memiliki terpaan lebih besar terhadap agen perubahan, memiliki tingkat pendidikan dan penghasilan yang tinggi, serta memiliki jejaring sosial yang jauh lebih luas dari orang kebanyakan. Dalam kasus AIMI, opinion leader adalah para Pengurus AIMI yang memanfaatkan jejaring personal dan profesionalnya secara optimal untuk menyebarluaskan inovasi, yakni mempromosikan dan mendukung pemberian ASI eksklusif melalui Internet dan media sosial. Selain itu, mengembangkan ruang lingkup targek khalayak AIMI yakni tidak hanya berfokus pada ibu-ibu, namun juga merangkul orangorang terdekat seperti pasangan dan keluarga menggambarkan betapa AIMI menyadari peran opinion leaders dalam menyukseskan promosi dan dukungan terhadap pemberian ASI eksklusif. Bahkan, AIMI berhasil menumbuhkan semangat dukungan yang tinggi dari kaum lelaki terbukti dengan terbentuknya komunitas @ IDAyah_ASI, meningkatnya jumlah partisipan lelaki dalam kelas-kelas EdukASI dan kegiatan offline lainnya yang diselenggarakan AIMI.

Kesembilan, Compatibility. Pengalaman dan nilai-nilai masyarakat Indonesia yang cenderung kolektivistik dan senang berbagi menjadi faktor yang mempermudah AIMI dalam mempromosikan dan mendukung pemberian ASI eksklusif kepada masyarakat Indonesia.

Kesepuluh, Infrastructure. Keberadaan infrastruktur yang sesuai dengan kebutuhan inovasi menjadi penentu keberhasilan difusi inovasi. Di saat sistem sosial yang ada telah sesuai dengan kebutuhan inovasi, AIMI memanfaatkan pula momentum perkembangan teknologi informasi dan komunikasi yang sangat pesat akselerasinya di Indonesia. Kemampuan Pengurus untuk melihat peluang yang dimiliki teknologi perlu mendapatkan perhatian khusus karena inilah kekuatan sekaligus tantangan terbesar yang dihadapi oleh Pengurus AIMI. Kombinasi faktor sistem sosial dan waktu yang tepat, inovasi teknologi yang sederhana dan memperpendek rantai informasi dan birokrasi seperti yang dilakukan AIMI ternyata memiliki 
kesesuaian satu sama lain dan memberikan kontribusi positif terhadap tingkat kecepatan adopsi inovasi.

Berkaitan dengan kesepuluh konsep kunci dalam dinamika Difusi Inovasi, lebih lanjut Rogers mengungkapkan bahwa proses mengadopsi inovasi memerlukan waktu (Rogers, 2003). Dalam setiap ide atau alternatif baru yang belum teruji manfaat dan resikonya, selalu terdapat ketidakpastian. Ada beberapa aksi dan pilihan yang harus diambil seseorang saat mengevaluasi kemungkinan mengadopsi dan mempraktikkan sebuah ide baru. Merujuk pada pemaparan Rogers tersebut maka dalam konteks kasus AIMI berikut adalah tahapan Innovation-Decision Process yang kemudian membentuk dan menggerakkan aktivisme komunitas melalui media sosial:

Berdasarkan pemaparan konsep-konsep kunci Difusi Inovasi dan dari hasil pemetaan proses tahapan inovasi-keputussan kedua belah pihak sebagaimana yang terlihat dalam Gambar 1 dan Gambar 2 tersebut, serta dengan menyandingkannya dengan motivasi, karakteristik dan kontruksi makna media sosial Pendiri dan Pengurus AIMI, maka secara sederhana dapat disajikan gambaran proses Pengurus AIMI membangun dan menggerakkan aktivisme komunitas AIMI melalui media sosial sebagai berikut:

\section{SIIMPULAN}

Proses AIMI dalam membangun dan menggerakkan komunitas AIMI di media sosial tergambar dalam tahapan innovationdecision process yang terdiri dari langkah mengoptimalisasi pengetahuan, persuasi, keputusan, implementasi dan konfirmasi. Seluruh proses ini menempatkan Pengurus dan para pengguna sebagai aktor penting yang menginterpretasi perkembangan TIK dan media sosial sebagai sebuah potensi. Konstruksi makna yang dibagikan di kalangan informan mengenai TIK dan media sosial ditanslasikan dalam pemanfaatan yang berhasil membesarkan AIMI. Semua tahapan ini berlangsung terus menerus sebagai upaya merespon kebutuhan komunitas sekaligus mendorong efektivitas dan efisiensi interaksi komunitas.

Karenanya, agar organisasinya dapat terus berkembang, AIMI harus dapat terus memanfaatkan karakteristik Pengurus yang termasuk dalam kategori early adopters dalam menilai kekuatan, kelemahan, peluang, dan ancaman teknologi komunikasi dan informasi serta perkembangan media baru demi optimalisasi kampanye agenda-agenda AIMI. Selain itu, perlu dilakukan upaya terobosan untuk menjangkau kalangan late adopters dan laggard yang belum terjangkau oleh kampanye online dan offline AIMI. Oleh karenanya AIMI perlu mengoptimalisasi jejaringnya, terutama berkaitan dengan para pemangku kepentingan lain untuk dapat bekerja bersama dalam mempromosikan pentingnya pemberian ASI eksklusif dan mendukung kegiatan menyusui.

\section{DAFTAR PUSTAKA}

Arisma, \& Kaylaku, S. (2012). Promoting \& Supporting Breastfeeding through Social Media: A Case Study from Indonesian Breastfeeding Mothers Association (AIMI). Asosiasi Ibu Menyusui Indonesia (AIMI).

Asosiasi Penyelenggara Jasa Internet Indonesia . (2012). Profil Pengguna Internet Indonesia 2012. Asosiasi Penyelenggara Jasa Internet Indonesia (APJJI).

Bain, R. (1937). Technology and State Government. American Sociological Review. Bijker, W. E. (2010). How is technology made?-That is the Question! Cambridge Journal of Economics 2010, 34, 63-76.

Cain, M., \& Mittman, R. (2002). Diffusion of Innovation in Health Care. Institute for the Future (IFTF). California: California HealthCare Foundation.

Denzin, N., \& Lincoln, Y. (1994). Introduction Entering the Field of Qualitative Research. Dalam N. Denzin, \& Y. Lincoln, Handbook of Qualitative Research. London: SAGE Publications.

Gladwell, M. (2010, October 4). SMALL CHANGE: Why the revolution will not be tweeted. Diambil kembali dari The New Yorker: http://www.newyorker.com/ reporting/2010/10/04/101004fa_fact gladwell? currentPage $=1$

Grazella, M. (2012, August 01). Jakarta Named the World's Most Active Twitter City. Diambil kembali dari The Jakarta Post: http://www. thejakartapost.com/news/2012/08/01/ jakarta-named-world-s-most-active-twitter- 
city.html

Hartoyo, N. M., \& Sirait, R. A. (2014). Politics, Young Voters and Sea of Change in 2014 Indonesian Legislative Election. 10th Biennial Convention of the Pacific and Asian Communication Association (PACA) 2014: "Beyond Asia: Communicating Asian Culture to The World”. Bandung: Pacific and Asian Communication Association.

Korda, H., \& Itani, Z. (2013). Harnessing Social Media for Health Promotion and Behaviour CHange. Health Promotion Practice, 14(1), 15-23.

Lievrouw, L., \& Livistone, S. (2006). The Social Shaping and Consequences of ICT. In L. Lievrouw, \& S. Livistone, The handbook of New Media Updates Student Edition. London: SAGE Publication.

Lupiyanto, R. (2014, April 8). Media Sosial dan Kualitas Elektoral. Diambil kembali dari Pos Bali: http://posbali.com/media-sosial-dankualitas-elektoral/

Neiger, B., Burton, S., R., T., Giraud-Carrier, C., \& Fagen, M. (2013). Evaluatinng Social media's Capacity to Develop Enggaged Audiences in Health Promotion Settings: Use of Twitter Metrics as a Case Study. Health Promotion Practice, 14(2), 157-162.
Nugroho, Y., \& Syarief, S. S. (2012). Seri fesmedia Asia: Melampaui Aktivisme click? Media Baru dan Proses Politik dalam Indonesia Kontemporer. Jakarta: FriedriechEbert-Stiftung Kantor Perwakilan Indonesia.

Rogers, E. M. (1986). Communication Technology: The New Media in Society. London: Sage Publication.

Rogers, E. M. (2003). Diffusion of Innovations, Fifth Edition. New York, USA: Free Press.

Rotman, D., Viewe, g. S., Yardi, S., Chi, E., Preece, J., Shneiderman, B., et al. (2011). From slacktivism to activism: participatory culture in the age of social media. Proceedings of the 2011 annual conference extended abstracts on Human factors in computing systems. New York, NY, USA: ACM.

Stake, R. (2005). Qualitative Case Studies. Dalam N. Denzin, \& Y. Lincoln, The Sage Handbook of Qualitative Research. California: Sage Publications.

Thajeb, H. (2013, June). Indonesia's AdvertisingDead or Alive. Jakarta, Indonesia. Dipetik October 11, 2014, dari http://www.slideshare. net/AdityaEkaCandraSuyon/indonesiaadvertising-dead-or-alive-june2013 